Pacific Journal of Mathematics

ON THE ORDER OF THE RECIPROCAL SET OF A BASIC SET 


\title{
ON THE ORDER OF THE RECIPROCAL SET OF A BASIC SET OF POLYNOMIALS
}

\author{
M. N. MIKH AIL
}

1. Introduction. For the general terminology used in this paper the reader is referred to J. M. Whittaker [2], [3]. Let

$$
p_{n}(z)=\sum_{i} p_{n i} z^{i}
$$

be a basic set, and let

$$
z^{n}=\sum_{i=0}^{D_{n}} \pi_{n i} p_{i}(z) .
$$

The order $\omega$ and type $\gamma$ of $\left\{p_{n}(z)\right\}$ are defined as follows. Let $M_{i}(R)$ be the maximum modulus of $p_{i}(z)$ in $|z| \leq R$. Let

$$
\omega_{n}(R)=\sum_{i}\left|\pi_{n i}\right| M_{i}(R),
$$

$$
\omega(R)=\limsup _{n \rightarrow \infty} \frac{\log \omega_{n}(R)}{n \log n},
$$

$$
\omega=\lim _{R \rightarrow \infty} \omega(R)
$$

and, for $0<\omega<\infty$, let

$$
\begin{gathered}
\gamma(R)=\limsup _{n \rightarrow \infty}\left\{\omega_{n}(R)\right\}^{1 /(n \omega)} e /(n \omega), \\
\gamma=\lim _{R \rightarrow \infty} \gamma(R) .
\end{gathered}
$$

If

$$
P_{n}(z)=\sum_{i} \pi_{n i} z^{i}
$$

Received July 2, 1952.

Pacific J. Math. 3 (1953), 617-623 
then $\left\{P_{n}(z)\right\}$ is called the reciprocal set of $\left\{p_{n}(z)\right\}$. We shall establish for certain basic sets new formulas expressing upper bounds of the order of the reciprocal set in terms of the data of the original set.

2. Theorem. The following theorem holds only if an infinity of $\pi_{n n} \neq 0$; then the whole proof should be carried out for those values of $n$ for which $\pi_{n n} \neq 0$. This is a genuine restriction since there are basic sets such that $\pi_{n n}=0$ for all $n$; for example, for $h=0,1,2, \ldots$, let

$$
\begin{aligned}
& p_{3 h}(z)=-\frac{1}{2} z^{3 h}+\frac{1}{2} z^{3 h+1}+\frac{1}{2} z^{3 h+2}, \\
& p_{3 h+1}(z)=\frac{1}{2} z^{3 h}-\frac{1}{2} z^{3 h+1}+\frac{1}{2} z^{3 h+2}, \\
& p_{3 h+2}(z)=\frac{1}{2} z^{3 h}+\frac{1}{2} z^{3 h+1}-\frac{1}{2} z^{3 h+2} .
\end{aligned}
$$

Notation. For a fixed $n$, let $p_{n h^{\prime}}$ be the set of all nonzero elements $p_{n h}$, and let

$$
\min _{h^{\prime}} p_{n h^{\prime}}=p_{n^{\prime}}
$$

THEOREM 1. Let $\left\{p_{n}(z)\right\}$ be a basic set of polynomials, such that

$$
\limsup _{n \rightarrow \infty} \frac{D_{n}}{n}=a
$$

and of increase less than order $\omega$ and type $\gamma$, and suppose that

$$
\kappa=\liminf _{n \rightarrow \infty} \frac{\log \left|\pi_{n n}\right|}{n \log n}
$$

and

$$
k=\liminf _{n \rightarrow \infty} \frac{\log \left|p_{n} \cdot\right|}{n \log n} .
$$

Then its reciprocal set is of order $\Omega$, where

i) if $k>\omega$, then $\Omega \leq \omega-\kappa$; 
ii) if $k \leq \omega$, then $\Omega \leq 2 \omega-\kappa-k$.

Proof. Let $\gamma_{1}>\gamma$; then in view of (4) we have

$$
\omega_{n}(R) \leq\left(\frac{n \omega \gamma_{1}}{e}\right)^{n \omega}
$$

for values of $n>n_{0}$ and for sufficiently large values of $R>R_{0}>1$. From (1), we have

$$
\left|\pi_{n n}\right| M_{n}(R) \leq \omega_{n}(R)
$$

Then

$$
\left|\pi_{n n}\right|\left|p_{n i}\right| R^{i} \leq \omega_{n}(R)
$$

that is

$$
\left|p_{n i}\right| \leq \frac{\omega_{n}(R)}{\left|\pi_{n n}\right|}
$$

Also

$$
\left|\pi_{i j}\right| M_{j}(R) \leq \omega_{i}(R)
$$

then

$$
\left|\pi_{i j}\right| \leq \frac{\omega_{i}(R)}{M_{j}(R)} \leq \frac{\omega_{i}(R)}{\min _{h^{\prime}}\left|p_{i h^{\prime}}\right|}=\frac{\omega_{i}(R)}{\left|p_{i} \cdot\right|}
$$

From the definition of a reciprocal set, and in view of (1), we get

$$
\Omega_{n}(R) \leq \sum_{i=0}^{D_{n}}\left|p_{n i}\right| \sum_{j}\left|\pi_{i j}\right| R^{j} \leq \frac{\omega_{n}(R)}{\left|\pi_{n n}\right|} R^{D_{n}} \sum_{i=0}^{D_{n}} \sum_{j}\left|\pi_{i j}\right|
$$

by (7); that is, by ( 8 ),

$$
\Omega_{n}(R) \leq \frac{\omega_{n}(R)}{\left|\pi_{n n}\right|} R^{D_{n}} \sum_{i=0}^{D_{n}} N_{i} \frac{\omega_{i}(R)}{\left|p_{i^{\prime}}\right|} .
$$


Then

$$
\begin{aligned}
\Omega_{n}(R) & \leq \frac{\omega_{n}(R)}{\left|\pi_{n n}\right|} R^{D_{n}} \cdot D_{n}\left\{F(R)+\sum_{i=n_{0}+1}^{D_{n}} \frac{\omega_{i}(R)}{\left|p_{i} \cdot\right|}\right\} \\
& \leq \frac{\omega_{n}(R)}{\left|\pi_{n n}\right|} R^{D_{n}} \cdot D_{n}\left\{F(R)+\sum_{i=n_{0}+1}^{D_{n}} \frac{\left(i \omega \gamma_{1}\right)^{i \omega}}{\left|p_{i} \cdot\right|}\right\} \text { by (6), }
\end{aligned}
$$

where $F(R)$ is a function independent of $n$.

Then for sufficiently large values of $n>n_{0}$ and $R>R_{0}$, we get

$$
\Omega_{n}(R) \leq \frac{\omega_{n}(R)}{\left|\pi_{n n}\right|} R^{D_{n}} \cdot D_{n}\left\{F(R)+D_{n}\left(\frac{n \omega \gamma_{1}}{k_{1} / \omega}\right)^{n \omega}\right\} \quad\left(\text { where } k_{1} \geq k\right) .
$$

\section{Hence:}

i) If $k>\omega$ (this implies $\left.k_{1}>\omega\right)$, then $\left(n \omega \gamma_{1} / n^{k_{1} / \omega}\right)^{n \omega}$, for values of $n>n_{0}$, will be a small quantity compared to $F(R)$. Therefore,

$\lim _{R \rightarrow \infty} \limsup _{n \rightarrow \infty} \frac{\log \Omega_{n}(R)}{n \log n}$

$\leq \lim _{R \rightarrow \infty} \limsup _{n \rightarrow \infty}\left\{\frac{\log \omega_{n}(R)}{n \log n}+\frac{D_{n} \log R}{n \log n}-\frac{\log \left|\pi_{n n}\right|}{n \log n}+\frac{\log D_{n}}{n \log n}+\frac{\log F(R)}{n \log n}\right\}$, in view of (2) and (3); then

$$
\Omega \leq \omega-\kappa
$$

ii If $k \leq \omega$, then as $k_{1}$ approaches $k$ we find that $F(R)$ will be very small compared to $\left\{n \omega \gamma_{1} / n^{k_{1} / \omega}\right\}$ for $n>n_{0}$. Therefore,

$$
\begin{aligned}
& \lim _{R \rightarrow \infty} \limsup _{n \rightarrow \infty} \frac{\log \omega_{n}(R)}{n \log n} \leq \lim _{R \rightarrow \infty} \limsup _{n \rightarrow \infty}\left\{\frac{\log \omega_{n}(R)}{n \log n}-\frac{\log \left|\pi_{n}\right|}{n \log n}\right. \\
&\left.+\frac{D_{n} \log R+2 \log D_{n}}{n \log n}+\frac{n \omega\left(1-\frac{k_{1}}{\omega}\right) \log n}{n \log n}+\frac{n \omega \log \omega \gamma_{1}}{n \log n}\right\}
\end{aligned}
$$


in view of (2) and (3); then

$$
\Omega \leq \omega-\kappa+\omega-k=2 \omega-\kappa-k .
$$

N. B. In the case of simple sets, the restriction mentioned above for $\pi_{n n}$ is satisfied. In this case we have

$$
-\kappa=\limsup _{n \rightarrow \infty} \frac{\log \left|p_{n n}\right|}{n \log n} .
$$

COROLLARY. If $\left\{p_{n}(z)\right\}$ is a simple set of polynomials,
i) if $k>\omega$, then $\Omega \leq \omega-\kappa$
where $\kappa=-\limsup _{n \rightarrow \infty} \frac{\log \left|p_{n n}\right|}{n \log n}$.
ii ) if $k \leq \omega$, then $\Omega \leq 2 \omega-\kappa-k$

3. Examples. We shall look at four examples.

i) Let $p_{n}(z)=n^{3 n} z^{n}-n^{2 n} z^{n-1}-n^{3 n} z^{n+1}$

$$
\begin{aligned}
& p_{n}(z)=n^{2 n} z^{n}-n^{3 n} \\
& p_{0}(z)=1 .
\end{aligned}
$$

then

$$
\begin{array}{rlr}
z^{n}=n^{-3 n} p_{n}(z) & +n^{-n}(n-1)^{-2(n-1)} p_{n-1}(z)+(n+1)^{-2(n+1)} p_{n+1}(z) \\
& +\left\{(n-1)^{(n-1)} n^{-n}+(n+1)^{(n+1)}\right\} p_{0}(z) & (n \text { odd }), \\
z^{n}=n^{-2 n} p_{n}(z)+n^{n} p_{0}(z) & \text { (n even). }
\end{array}
$$

By Theorem (1) of [1], we get $\omega=1$. Since $\kappa=-3, k=2$, we get, according to case $i$ ) of the theorem, $\Omega \leq 1+3=4$. This is true because $\Omega=4$ by Corollary (1.1) of [1].

N. B. This example and the following examples show that the values given in the conclusion of the above theorem are "best possible."

ii ) Let $p_{n}(z)=n^{2 n} z^{n}-n^{3 n / 2} z^{2 n}-n^{2 n}$

$(n$ odd $)$,

$$
\left.p_{n}(z)=\left(\frac{n}{2}\right)^{3 n / 2} z^{n}-\left(\frac{n}{2}\right)^{2 n}, \text { with } p_{0}(z)=1 \quad \because \text { even }\right),
$$


Then

$$
\begin{array}{ll}
z^{n}=n^{-2 n} p_{n}(z)+n^{-7 n / 2} p_{2 n}(z)+\left(1+n^{n / 2}\right) p_{0}(z) & \text { ( } n \text { odd ) } \\
z^{n}=\left(\frac{n}{2}\right)^{-3 n / 2} p_{n}(z)+\left(\frac{n}{2}\right)^{n / 2} p_{0}(z) & \text { ( } n \text { even) }
\end{array}
$$

Applying theorem ( 1 ) of [1], we get $\omega=1 / 2$. Now $k=-2, k=3 / 2$. Then according to case $i$ ), of the theorem, we get

$$
\Omega \leq \frac{1}{2}+2
$$

This is true because $\Omega=5 / 2$ by Corollary (1.1) of [1].

iii ) Let $p_{n}(z)=n^{n} z^{n}-n^{n / 2} z^{n-1}-n^{3 n / 2}$

$$
\begin{aligned}
& p_{n}(z)=(n+1)^{(n+1)} z^{n}-(n+1)^{2(n+1)} z^{(n+1)} \\
& -(n+1)^{5(n+1) / 2} \\
& p_{0}(z)=1
\end{aligned}
$$$$
(n \text { even }) \text {, }
$$

Then

$$
\begin{gathered}
z^{n}=\frac{1}{1-n^{n / 2}}\left\{n^{-n} p_{n}(z)+n^{-3 n / 2} p_{n-1}(z)+\left(n^{n / 2}+n^{n}\right) p_{0}(z)\right\} \quad(n \text { odd }), \\
z^{n}=\frac{1}{1-(n+1)^{(n+1) / 2}}\left\{(n+1)^{-(n+1)} p_{n}(z)\right. \\
\left.+p_{n+1}(z)+2(n+1)^{3(n+1) / 2} p_{0}(z)\right\} \quad \text { (n even). }
\end{gathered}
$$

Applying theorem (1) of [1], we get $\omega=1$. Now $\kappa=-1, k=1 / 2$. Then according to case ii) of the theorem, we get

$$
\Omega \leq 2+1-\frac{1}{2}=\frac{5}{2}
$$

This is true because $\Omega=5 / 2$ by Corollary (1.1) of [ 1$]$. 
iv ) Let $p_{n}(z)=\frac{2^{(n-1)}}{2^{(n-1)} n^{2 n}+(n-1)^{3(n-1)}} z^{n}+\frac{2^{(n-1)} n^{n}}{2^{(n-1)} n^{2 n}+(n-1)^{3(n-1)}}$

$$
\begin{aligned}
& +\frac{2^{2(n-1)}(n-1)^{(n-1)}}{2^{(n-1)} n^{2 n}+(n-1)^{3(n-1)}} z^{n-1} \quad \text { (n odd), } \\
& p_{n}(z)=\frac{2^{2 n}(n+1)^{2(n+1)}}{2^{n} n^{n}(n+1)^{2(n+1)}+n^{4 n}} z^{n}-\frac{n^{n}}{2^{n}(n+1)^{2(n+1)}+n^{3 n}} z^{n+1} \\
& -\frac{n^{n}(n+1)^{(n+1)}}{2^{n}(n+1)^{2(n+1)}+n^{3 n}} z^{2 n+2} \quad(n \text { even), } \\
& p_{0}(z)=1 .
\end{aligned}
$$

Then

$$
\begin{aligned}
& z^{n}=n^{2 n} p_{n}(z)-n^{3 n} p_{2 n}(z) \\
& -(n-1)^{2(n-1)} p_{n-1}(z)-n^{5 n} p_{2 n+1}(z) \quad(n \text { odd }), \\
& \left.z^{n}=\left(\frac{1}{2} n\right)^{n} p_{n}(z)+\left(\frac{1}{2} n\right)^{2 n} p_{n+1}(z) \quad \text { ( } n \text { even }\right)
\end{aligned}
$$

Applying theorem (1) of [1], we get $\omega=1$. Now $\kappa=2, k=-3$. Then according to case ii) of the theorem, we get

$$
\Omega \leq 2-2+3=3 \text {. }
$$

This is true because $\Omega=3$ by Corollary (1.1) of [1].

\section{REFERENCES}

1. M. N. Mikhail, Basic sets of polynomials and their reciprocal, product and quotient sets, Duke Math. J. (to appear).

2. J. M. Whittaker, Interpolatory function theory, Cambridge, England, 1935.

3. , Sur les séries de base de polynomes quelconques, Paris, 1949.

\section{Birkbeck College}





\section{PACIFIC JOURNAL OF MATHEMATICS}

\section{EDITORS}

\author{
R. M. BOEINSON \\ University of California \\ Berkeley 4, California \\ E. HewitT \\ University of Washington \\ Seattle 5 , Washington
}

\section{R. P. DILWOR TH}

California Institute of Technology

Pasadena 4, California

E. F. BECKENBACH

University of California

Los Angeles 24, California

\section{ASSOCIATE EDITORS}

$\begin{array}{ll}\text { H. BUSEMANN } & \text { P. R. HALMOS } \\ \text { HERBERT FFDERER } & \text { IIEINZ HOPF } \\ \text { MARSHALL IJALL } & \text { R. D. JAMES }\end{array}$

\author{
BøRGE JESSEN \\ PAUL LÉVY \\ GEORGE PÓLYA
}

\author{
J. J. STOKER \\ E. G. STR AUS \\ KÔSAKU YOSIDA
}

\section{SFONSORS}

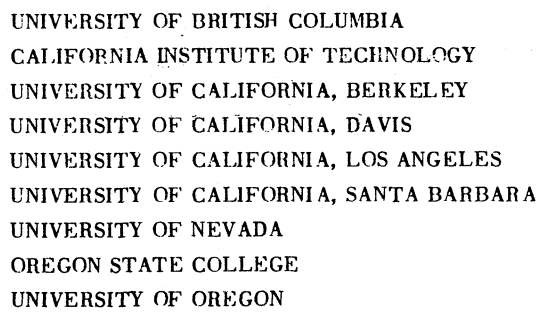

\author{
UNIVERSITY OF SOUTHERN CALIFORNIA \\ STANFORD RESEARCH INSTITUTE \\ STANFORD UNIVERSITY \\ WASHINGTON STATE COLLEGE \\ UNIVERSITY OF WASHINGTON \\ AMERICAN MATHEMATICAL SOCIETY \\ NATIONAL BUREAU OF STANDARDS, \\ INSTITUTE FOR NUMERICAL ANALYSIS
}

Mathematical papers intended for publication in the Pacific Journal of Mathematics should be typewritten (double spaced), and the author should keep a complete copy. Manuscripts may be sent to any of the editors except Robinson, whose term expires with the completion of the present volume; they might also be sent to M.M. Schiffer, Stanford University, Stanford, California, who is succeeding Robinson. All other communications to the editors should be addressed to the managing editor, E. F. Beckenbach, at the address given above.

Authors are entitled to receive 100 free reprints of their published papers and may obtain additional copies at cost.

The Pacific Journal of Mathematics is published quarterly, in March, June, September, and December. The price per volume (4 numbers) is $\$ 8.00$; single issues, $\$ 2.50$. Special price to individual faculty members of supporting institutions and to individual members of the American Mathematical Society: $\$ 4.00$ per volume; single issues, $\$ 1.25$.

Subscriptions, orders for back numbers, and changes of address should be sent to the publishers, University of California Press, Berkeley 4, California.

Printed at Ann Arbor, Michigan. Entered as second class matter at the Post Office, Berkeley, California.

\section{UNIVERSITY OF CALIFORNIA PRESS • BERKELEY AND LOS ANGELES}




\section{Pacific Journal of Mathematics}

\section{Vol. 3, No. 3 \\ May, 1953}

L. Carlitz, Some theorems on generalized Dedekind sums ............ 513

L. Carlitz, The reciprocity theorem for Dedekind sums ............. 523

Edward Richard Fadell, Identifications in singular homology theory..... . . 529

Harley M. Flanders, A method of general linear frames in Riemannian

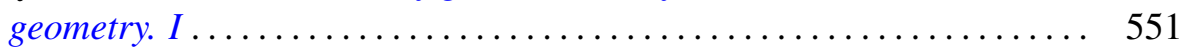

Watson Bryan Fulks, The Neumann problem for the heat equation ........ 567

Paul R. Garabedian, Orthogonal harmonic polynomials.............. 585

R. E. Greenwood and Andrew Mattei Gleason, Distribution of round-off errors for running averages .............................. 605

Arthur Eugene Livingston, The space $H^{p}, 0<p<1$, is not normable ... 613

M. N. Mikhail, On the order of the reciprocal set of a basic set of polynomials .......................................... 617

Louis Joel Mordell, On the linear independence of algebraic numbers . . . . 625

Leo Sario, Alternating method on arbitrary Riemann surfaces .......... 631

Harold Nathaniel Shapiro, Iterates of arithmetic functions and a property of the sequence of primes.............................. 647

H. Shniad, Convexity properties of integral means of analytic functions . . . . 657

Marlow C. Sholander, Plane geometries from convex plates ........... 667 